\title{
The association between adjustment disorder diagnosed at psychiatric treatment facilities and completed suicide
}

This article was published in the following Dove Press journal:

Clinical Epidemiology

13 March 2010

Number of times this article has been viewed

\author{
Jaimie L Gradus ${ }^{1,2}$ \\ Ping Qin ${ }^{3}$ \\ Alisa K Lincoln ${ }^{4}$ \\ Matthew Miller ${ }^{5}$ \\ Elizabeth Lawler 6 \\ Timothy L Lash ${ }^{2,7}$ \\ 'National Center for PTSD VA Boston \\ Healthcare System, Boston, MA, USA; \\ ${ }^{2}$ Department of Epidemiology, Boston \\ University School of Public Health, \\ Boston, MA, USA; ${ }^{3}$ National Centre \\ for Register-based Research, Aarhus \\ University, Aarhus, Denmark; ${ }^{4}$ Health \\ Sciences and Sociology Departments, \\ Northeastern University, Boston, MA, \\ USA; ${ }^{5}$ Department of Health Policy \\ and Management, Harvard University \\ School of Public Health, Boston, \\ MA, USA; ${ }^{6}$ Department of Medicine, \\ Harvard University, Boston, MA, USA; \\ ${ }^{7}$ Department of Clinical Epidemiology, \\ Aarhus University Hospital, Aarhus, \\ Denmark
}

Correspondence: Jaimie L Gradus

National Center for Posttraumatic Stress Disorder, Women's Health Sciences

Division, VA Boston Healthcare System, I50 South Huntington Avenue (I I 6B-3),

Boston, MA 02130, USA

Tel + I 8573646688

Fax +I 8573644515

Email jaimie.gradus@va.gov

\begin{abstract}
Adjustment disorder is a diagnosis given following a significant psychosocial stressor from which an individual has difficulty recovering. The individual's reaction to this event must exceed what would be observed among similar people experiencing the same stressor. Adjustment disorder is associated with suicidal ideation and suicide attempt. However the association between adjustment disorder and completed suicide has yet to be examined. The current study is a population-based case control study examining this association in the population of Denmark aged 15 to 90 years. All suicides in Denmark from 1994 to 2006 were included, resulting in 9,612 cases. For each case, up to 30 controls were matched on gender, exact date of birth, and calendar time, yielding 199,306 controls. Adjustment disorder diagnosis was found in $7.6 \%$ of suicide cases and $0.52 \%$ of controls. Conditional logistic regression analyses revealed that those diagnosed with adjustment disorder had 12 times the rate of suicide as those without an adjustment disorder diagnosis, after controlling for history of depression diagnosis, marital status, income, and the matched factors.
\end{abstract}

Keywords: adjustment disorder, suicide, case-control study

Adjustment disorder is a diagnosis given following a significant psychosocial stressor from which an individual has difficulty recovering (eg, death of a loved one, failure to attain an important goal, termination from employment, or other similar events). To meet diagnostic criteria for this disorder, this reaction must exceed what would be observed among similar people experiencing the same stressor, and the stressor must occur no more than one month before symptom onset. ${ }^{1}$

Suicidal behavior is more common among people diagnosed with adjustment disorder than people without this diagnosis. Patients hospitalized in a psychiatric department with an adjustment disorder diagnosis have a higher prevalence of preceding suicide attempts at admission (96\%) than patients without adjustment disorders (78.6\%). ${ }^{2}$ Further, among adolescents admitted to a psychiatric hospital, adjustment disorder was more common among those hospitalized for a suicide attempt than among youths with no history of suicide attempt. ${ }^{3}$ This difference has been observed in other populations as well. Among patients hospitalized in Switzerland, those brought to the psychiatric emergency room for a suicide attempt were more likely to have had an adjustment disorder diagnosis (47.9\%) than those brought to the psychiatric emergency room for other reasons (22.3\%). ${ }^{4}$ Additionally, adjustment disorders were the most common diagnosis among patients under the age of 21 years in a retrospective study of patients who had made a suicide attempt in Singapore. ${ }^{5}$

While there is evidence of an association between adjustment disorders and attempts, the association between adjustment disorders and completed suicide has yet to 
be examined. Studies of the association between adjustment disorder and suicidal behavior are an imperfect substitute for studies of the association with suicidal behavior, because there are important differences between people who think about or attempt suicide, and people who die by suicide. ${ }^{6}$ Therefore, the current study aimed to examine adjustment disorder as a predictor of completed suicide. We hypothesized that people diagnosed with adjustment disorder would have a higher rate of completed suicide than people without this diagnosis.

\section{Methods}

\section{Study population}

The source population for the current study was the entire population of Denmark aged 15 to 90 years at risk for suicide between January 1st, 1994 and December 31st, 2006. Participants had to reside in Denmark for the entire calendar year before suicide (or the match date in control participants) to allow us to collect complete data on social variables. The primary criterion for identification as a case in the study was having completed suicide according to the definition below, which yielded 9,612 cases. We matched up to 30 controls from a $25 \%$ representative sample of the Danish population to suicide cases on gender, date of birth, and calendar time, yielding 199,306 controls. If 30 or fewer matched controls were available, we selected all available controls. If more than 30 controls matched a case, then we randomly selected 30 from those available.

\section{Data collection}

We obtained data for the study from the Danish national medical and administrative registries. The Cause-of-Death Register contains information on cause and date of death, and was used to identify suicide cases. ${ }^{7}$ The Danish Psychiatric Central Register contains dates on outpatient and inpatient psychiatric treatment in Denmark, as well as validated diagnoses, and was used to obtain data on adjustment disorder and psychiatric covariate diagnoses. ${ }^{8}$ Finally, we used the Civil Registration System for control participant selection, ${ }^{9}$ and we used the Integrated Database for Labour Market Research to obtain data on social variables. ${ }^{7}$ We linked these registries using the Civil Registration Number, which is assigned to all citizens and residents of Denmark.

\section{Variable definitions}

Appendix 1 lists the variables involved in the current analyses and their International Classification of Disease codes. ${ }^{10,11}$ Suicide is classified as a cause of death in Denmark as follows. After any unnatural death, independent forensic medical doctors conduct an inquest. This inquest involves collecting information about the death itself and the deceased from the deceased's physician, family and friends, and the person(s) who discovered the body. Information is collected about place of death, method of dying, and presence of a suicide note. If the cause of death is still uncertain following this inquest, an autopsy is conducted. The final determination of death from suicide is made by the independent forensic doctor based on information from all of these sources. This process has been described in more detail elsewhere. ${ }^{12}$

We included only psychiatric diagnoses that occurred before the first adjustment disorder diagnosis as potential confounders and modifiers, as it is possible that these disorders are on the causal pathway between adjustment disorder and suicide. In addition, we used only primary diagnoses to identify both adjustment disorder and psychiatric covariates. Psychiatic covariates included depression, substance abuse, and anxiety disorders. For demographic covariates, we assessed marital status, income, and geographic location. Marital status was recorded as of November in the calendar year before suicide date or match date for control participants. Income was recorded in the calendar year before suicide date or match date for control participants, and was categorized into quartiles within strata of sex and age groups.

\section{Statistical analyses}

We calculated the frequency and proportion of cases and controls within categories of the exposure and covariates. We used conditional logistic regression used to estimate the association between adjustment disorder diagnosis and completed suicide. As risk set sampling was used to sample control participants, the odds ratios obtained from these conditional logistic regression analyses provide unbiased estimates of the corresponding rate ratios. ${ }^{13}$ We used changein-estimate methods as a model building strategy to select confounders from the candidate psychiatric and demographic covariates listed above. ${ }^{14}$

To address potential misclassification of psychiatric disorders, we conducted a bias analysis to assess the impact of residual confounding by depression, substance abuse, and anxiety disorders. ${ }^{15}$ We calculated the corrected estimates using a sensitivity of $50 \%, 70 \%$, and $90 \%$ and assumed that misclassification was nondifferential and independent for cases and controls because the data were recorded prospectively. In addition, we assumed that specificity would be perfect, given the extensive process for psychiatric disorder validation that occurs in Denmark. Finally, because cases may 
have been treated in a psychiatric facility more than controls before committing suicide, and therefore would have more accurate psychiatric disorder confounder classification, we conducted a bias analysis to examine differential imperfect sensitivity of confounder classification among cases and controls. For this analysis, we used a sensitivity for cases of 0.92 (the minimum sensitivity that resulted in nonnegative cells in the corrected tables) and a sensitivity for controls of 0.5. We used SAS software (version 9.1.3; SAS Institute, Cary, NC) to conduct all analyses.

\section{Results}

The descriptive characteristics of the cases and controls are displayed in Table 1 . Suicide cases were primarily male (71\%), single (58\%), and in the lowest income quartile (42\%). The initial conditional logistic regression analysis, adjusting for the control-to-case matching on gender, date of birth, and calendar time, revealed that those diagnosed with adjustment disorder had 19 times the rate of suicide of people without this preceding diagnosis $(95 \%$ confidence interval [CI]: 17-21). Using the change-in-estimate model

Table I Characteristics of suicide cases and controls, Denmark 1994-2006

\begin{tabular}{|c|c|c|}
\hline & $\begin{array}{l}\text { Cases } \\
(n=96 \mid 2)\end{array}$ & $\begin{array}{l}\text { Controls } \\
(n=199,306)\end{array}$ \\
\hline \multicolumn{3}{|l|}{ Gender } \\
\hline Male & 6837 (71\%) & I42,865 (72\%) \\
\hline Female & 2775 (29\%) & $56,44 \mathrm{I}(28 \%)$ \\
\hline \multicolumn{3}{|l|}{ Age group } \\
\hline 15-34 years & $|70|(\mid 8 \%)$ & $42,627(21 \%)$ \\
\hline $35-54$ years & $3608(38 \%)$ & $93,703(47 \%)$ \\
\hline $55-74$ years & $28 \mid 8(29 \%)$ & $5 I, 176(26 \%)$ \\
\hline $75-90$ years & I 485 (I5\%) & II,800 (5.9\%) \\
\hline \multicolumn{3}{|l|}{ Marital status } \\
\hline Married & $3|2|(32 \%)$ & $107,758(54 \%)$ \\
\hline Cohabitating & $823(8.0 \%)$ & $25,130(13 \%)$ \\
\hline Single & $5569(58 \%)$ & $64,47 \mid(32 \%)$ \\
\hline Unmarried minor & 99 (1.0\%) & $1947(1.0 \%)$ \\
\hline \multicolumn{3}{|l|}{ Income } \\
\hline Lowest income quartile & 4014 (42\%) & $49,322(25 \%)$ \\
\hline Second income quartile & $2242(23 \%)$ & $50,011(25 \%)$ \\
\hline Third income quartile & 1786 (19\%) & $49,952(25 \%)$ \\
\hline Highest income quartile & $1570(16 \%)$ & $50,021(25 \%)$ \\
\hline Adjustment disorder & 728 (7.6\%) & 1040 (0.52\%) \\
\hline \multicolumn{3}{|l|}{ Other psychiatric diagnoses } \\
\hline Depression & $1713(18 \%)$ & $2542(1.3 \%)$ \\
\hline Substance abuse & 1024 (I I\%) & $2686(1.4 \%)$ \\
\hline Anxiety disorders & $352(3.7 \%)$ & 1309 (0.66\%) \\
\hline
\end{tabular}

building method, we identified depression, marital status, and income as confounders of this association. Those with adjustment disorder had 12 times the rate of suicide as those without a preceding adjustment disorder, when controlling for these variables in addition to the matched factors $(95 \%$ CI: 11-14).

We conducted a bias analysis to evaluate whether residual confounding by psychiatric covariates would affect the observed associations between adjustment disorder and suicide, assuming a valid bias model and the accuracy of the values assigned to the bias parameters. The results of this analysis are displayed in Table 2. At all levels of sensitivity tested, an association between adjustment disorder and suicide remained. Finally, we conducted a bias analysis to explore differential misclassification of psychiatric covariates among cases and controls, given that cases may have been treated in a psychiatric facility more than controls before committing suicide, and may therefore have a more accurately recorded psychiatric history (Table 3). Assuming a valid bias model, and accurate values assigned to parameters, it does not appear from these results that dif-

Table 2 Bias analysis exploring the effects of imperfect nondifferential sensitivity of psychiatric disorders on the association between adjustment disorder and suicide ${ }^{\mathrm{a}}$

\begin{tabular}{ll}
\hline & $\begin{array}{l}\text { Adjustment disorder } \\
\text { Odds ratio }\end{array}$ \\
\hline Adjusted for depression (uncorrected) & 7.5 \\
Depression sensitivity $=0.5$ & 4.9 \\
Depression specificity $=1.0$ & \\
Depression sensitivity $=0.7$ & 6.2 \\
Depression specificity $=1.0$ & \\
Depression sensitivity $=0.9$ & 7.1 \\
Depression specificity $=1.0$ & \\
Adjusted for substance abuse (uncorrected) & 11 \\
Substance abuse sensitivity $=0.5$ & 7.8 \\
Substance abuse specificity $=1.0$ & \\
Substance abuse sensitivity $=0.7$ & 9.2 \\
Substance abuse specificity $=1.0$ & 10 \\
Substance abuse sensitivity $=0.9$ & \\
Substance abuse specificity $=1.0$ & 14 \\
Adjusted for anxiety disorders (uncorrected) & 14 \\
Anxiety disorders sensitivity $=0.5$ & 12 \\
Anxiety disorders specificity $=1.0$ & \\
Anxiety disorders sensitivity $=0.7$ & 13 \\
Anxiety disorders specificity $=1.0$ & \\
Anxiety disorders sensitivity $=0.9$ & \\
Anxiety disorders specificity $=1.0$ & \\
\hline Note $W$ set a sper & \\
\hline
\end{tabular}

Notes: aWe set all specificity equal to 1.0 , because the probability that a person truly without these disorders would be treated at a psychiatric facility with a diagnosis of these disorders is near zero. 
Table 3 Bias analysis exploring the effects of differential imperfect sensitivity of psychiatric disorders on association between adjustment disorder and suicide ${ }^{\mathrm{a}}$

\begin{tabular}{ll}
\hline & $\begin{array}{l}\text { Adjustment } \\
\text { disorder } \\
\text { Odds ratio }\end{array}$ \\
\hline Adjusted for depression (uncorrected) & 7.5 \\
$\begin{array}{l}\text { Depression sensitivity cases }=0.92 \text {; controls }=0.5 \\
\text { Depression specificity = I.0 }\end{array}$ & 4.9 \\
Adjusted for substance abuse (uncorrected) & $1 \mathrm{I}$ \\
$\quad$ Substance abuse sensitivity cases $=0.92$; controls $=0.5$ & 7.8 \\
Substance abuse specificity $=1.0$ & \\
Adjusted for anxiety disorders (uncorrected) & 14 \\
$\begin{array}{l}\text { Anxiety disorder sensitivity cases }=0.92 ; \text { controls }=0.5 \\
\text { Anxiety disorder specificity }=1.0\end{array}$ & 12 \\
\hline
\end{tabular}

Notes: ${ }^{a}$ We set all specificity equal to 1.0 , because the probability that a person truly without these disorders would be treated at a psychiatric facility with a diagnosis of these disorders is near zero.

ferential sensitivity of classification of psychiatric disorder confounders among cases and controls would have a significant impact on the results.

\section{Discussion}

Consistent with our hypotheses, we found that adjustment disorder was associated with an increased rate of completed suicide, controlling for history of depression, income, marital status, and the matched factors. Possible mechanisms that could account for this observed association include subsyndromal psychiatric symptoms, particularly depressed mood, which are associated with suicidal ideation among adolescents and with adjustment disorder. ${ }^{16}$ In addition, stressful events that may result in an adjustment disorder diagnosis, which were not assessed in the current study, are associated with suicidal behavior among adolescents and young adults. ${ }^{17}$

The current investigation has limitations worth noting. First, we restricted psychiatric covariates to the period before adjustment disorder diagnosis and only used primary diagnoses from the Psychiatric Central Register (and not secondary diagnoses). It is possible that there is residual confounding of our observed adjustment disorder and suicide associations due to underascertainment of comorbid psychiatric illness. Because of this concern, we conducted a bias analysis, and found that even with a sensitivity of confounder classification of $50 \%$, the associations between adjustment disorder and suicide could not be explained by this type of misclassification. Second, it is possible that cases were treated in a psychiatric facility more frequently before committing suicide, and therefore would have better psychiatric confounder documentation than controls. We conducted a bias analysis to address this concern. Assuming a valid bias model, it appears that this differential misclassification would not have had a substantial impact on the results of the current study. Finally, we only included psychiatric diagnoses that were obtained at a psychiatric setting in Denmark. It is possible to be diagnosed with a psychiatric disorder at a somatic hospital in Denmark, and therefore the exposed participants in the current study may represent more severe cases of adjustment disorder, which may in turn be more strongly associated with suicide. We examined the number of adjustment disorder cases with a primary discharge code from somatic hospitals in the same time period, and there were too few to conduct a separate set of analyses on this group to see if the pattern of results was different from those presented here.

Despite these limitations, the current study is the first to report on the relation between adjustment disorder and completed suicide. Research to date has focused on the association between adjustment disorder and suicidal ideation or suicidal attempts. The current study examined the association between adjustment disorder and completed suicide using a population-based sample and prospectively collected data. The results of this study highlight completed suicide as an important potential sequelae of adjustment disorder diagnosis - one that warrants increased attention from researchers and clinician's alike.

\section{Acknowledgments}

We would like to thank Preben Bo Mortensen for enabling access to the data and for providing research resources. The authors report no conflicts of interest in this work.

\section{References}

1. World Health Organization. The ICD-10 Classification of Mental and Behavioural Disorders, Diagnostic Criteria for Research. Geneva, Switzerland: World Health Organization; 1993.

2. Kryzhanovskaya L, Canterbury R. Suicidal behavior in patients with adjustment disorders. Crisis. 2001;22:125-131.

3. Goldston DB, Daniel SS, Reboussin BA, Reboussin DM, Kelley AE, Frazier PH. Psychiatric diagnoses of pervious suicide attempters, firsttime attempters, and repeat attempters on an adolescent inpatient psychiatry unit. J Am Acad Child Adolesc Psychiatry. 1998;37:924-932.

4. Schnyder U, Valach L. Suicide attempters in a psychiatric emergency room population. Gen Hosp Psychiatry. 1997;19:119-129.

5. Wai BHK, Hong C, Heok KE. Suicidal behavior among young people in Singapore. Gen Hosp Psychiatry. 1999;21:128-133.

6. Maris RW, Berman AL, Silverman MM. Introduction to the study of suicide. In: Maris RW, Berman AL, Silverman MM, editors. Comprehensive Textbook of Suicidology. New York, NY: The Guilford Press; 2000. p. 3-25.

7. Qin P, Agerbo E, Mortensen PB. Suicide risk in relation to socioeconomic, demographic, psychiatric, and familial factors: A national register-based study of all suicides in Denmark, 1981-1997. Am J Psychiatry. 2003;160:765-772. 
8. Munk-Jørgemsen P, Mortensen PB. The Danish Psychiatric Central Register. Dan Med Bull. 1997;44:82-84.

9. Pedersen CB, Gøtzsche H, Møller J, Mortensen PB. The Danish civil registration system. A cohort of eight million persons. Dan Med Bull. 2006;53:441-449.

10. World Health Organization. Manual of the International Classification of Diseases (ICD-8). Geneva, Switzerland: World Health Organization; 1967.

11. Janca A, Ustun TB, van Drimmelen J, Dittmann V, Isaac M. ICD-10 Symptom Checklist for Mental Disorders, Version 1.1. Geneva: World Health Organization, 1994.

12. Statens Institute for Folkesundhed [National Institute for Public Health]. Selvmord i Danmark - Markant fald i selvmord, menstigende antal selvmordsfprsøge. Hvorfor? [Suicide in Denmark - a decrease in suicide completion but a increase in suicide attempt. Why?] København: Kailow Graphic A/S; 2005.
13. Rothman KJ, Greenland S, Lash TL. Case-control studies. In: Rothman KJ, Greenland S, Lash TL, editors. Modern Epidemiology. 3rd ed. Philadelphia, PA: Lippincott, Williams \& Wilkins; 2008. p. 111-127.

14. Greenland S. Introduction to regression modeling. In: Rothman KJ, Greenland S, Lash TL, editors. Modern Epidemiology. 3rd ed. Philadelphia, PA: Lippincott, Williams \& Wilkins; 2008. p. 418-458.

15. Greenland S, Lash TL. Bias analyses. In: Rothman KJ, Greenland S, Lash TL, editors. Modern Epidemiology. 3rd ed. Philadelphia, PA: Lippincott, Williams \& Wilkins; 2008:345-380.

16. Pelkonen M, Marttunen M, Henriksson M, Lönnqvist, J. Suicidality in adjustment disorder: Clinical characteristics of adolescent outpatients. Eur J Child Adolesc Psychiatry. 2005;14:174-180.

17. Beautrais AL, Joyce P, Mulder RT. Precipitating factors and life events in serious suicide attempts among youths aged 13 through 24 years. J Am Acad Child Adolesc Psychiatry. 1997;36(11):1543-1551. 
Appendix I Definition of variables used in the current study

\begin{tabular}{|c|c|c|}
\hline & $\begin{array}{l}\text { ICD-8 Code } \\
(1981-1993)\end{array}$ & $\begin{array}{l}\text { ICD-10 Code } \\
(1994-2006)\end{array}$ \\
\hline Adjustment disorder & - & F43.2 \\
\hline \multicolumn{3}{|l|}{ Depression } \\
\hline Depressive episodes & $296,300.4$ & F32 \\
\hline Recurrent depressive disorder & $296,300.4$ & F33 \\
\hline Dysthymia & 300.4 & F34.I \\
\hline \multicolumn{3}{|l|}{ Substance abuse } \\
\hline $\begin{array}{l}\text { Mental/behavioral disorders } \\
\text { due to use of alcohol }\end{array}$ & 291,303 & FIO \\
\hline $\begin{array}{l}\text { Mental/behavioral disorders } \\
\text { due to use of drugs }\end{array}$ & 294,304 & FII-FI9 \\
\hline \multicolumn{3}{|l|}{ Anxiety disorders } \\
\hline Other anxiety disorders & 300 & $\mathrm{~F} 40$ \\
\hline Phobic anxiety disorders & 300.2 & F4I \\
\hline Obsessive-compulsive disorder & 300.3 & $\mathrm{~F} 42$ \\
\hline Completed suicide & - & $\times 60-X 84$ \\
\hline
\end{tabular}

Abbreviation: ICD, International Classification of Disease.

\section{Publish your work in this journal}

Clinical Epidemiology is an international, peer-reviewed, open access journal focusing on disease and drug epidemiology, identification of risk factors and screening procedures to develop optimal preventative initiatives and programs. Specific topics include: diagnosis, prognosis, treatment, screening, prevention, risk factor modification, systematic

Submit your manuscript here: http://www.dovepress.com/clinical-epidemiology-journal

\section{Dovepress}

reviews, risk \& safety of medical interventions, epidemiology \& biostatical methods, evaluation of guidelines, translational medicine, health policies \& economic evaluations. The manuscript management system is completely online and includes a very quick and fair peer-review system, which is all easy to use. 